\title{
QUALIDADE NO ATENDIMENTO COMO FATOR DE COMPETITIVIDADE: ESTUDO REALIZADO EM UMA MICROEMPRESA FAMILIAR DO RAMO DE CONFECÇÕES DE LUPIONÓPOLIS-PR
}

\author{
Thais Rubia Ferreira Lepre, Érica Aparecida do Nascimento Crão, Sandra Severiano Moreira \\ Universidade do Oeste Paulista, UNOESTE, CURSO, Presidente Prudente, SP. E-mail: thaisrubia@unoeste.br
}

\begin{abstract}
RESUMO
Com um mercado em constante mudança, e a cada dia mais competitivo, para manter-se, as microempresas familiares precisam obter excelência no serviço, já que competem com organizações de grande porte, um diferencial é oferecer qualidade no atendimento, com objetivo de fidelizar os clientes e ainda destacar-se dos concorrentes. Sendo assim esta pesquisa é de suma importância para qualquer microempresa familiar, contribuindo com informações valiosas no difícil caminho de fidelização dos seus clientes. Além disso, também beneficiará microempresários, ajudando-os a compreender que um bom atendimento pode ser um diferencial competitivo, capaz de alavancar as suas vendas. Dessa maneira, o objetivo desta pesquisa recai em analisar o estado atual do atendimento de uma microempresa familiar, do ramo de confecções, situada na cidade de Lupionópolis-PR e propor formas de torná-la mais competitiva através do melhoramento das relações com o cliente. Quanto à metodologia, a pesquisa foi realizada através de abordagem qualitativa, tendo o estudo de caso como método condutor e a pesquisa bibliográfica, aliada a questionário e entrevista como instrumento de coleta de dados. Constatou-se com esta análise, que a implementação de banco de dados, pós venda, e treinamento dentro da empresa é capaz de melhorar o relacionamento com os clientes, fazendo com que a empresa obtenha excelência no atendimento, tornando-se mais competitiva.
\end{abstract}

Palavras-chave: Microempresa Familiar. Marketing. Qualidade no Atendimento. Fidelização.

\section{QUALITY IN ATTENDANCE AS COMPETITIVE FACTOR: STUDY PERFORMED ON A FAMILY MANUFACTURE BRANCH MICROENTERPRISE LUPIONÓPOLIS-PR}

\begin{abstract}
With a constantly changing market, and increasingly competitive, to keep the family microenterprises need to achieve excellence in service, as compete with large organizations, a differential is to offer quality service, in order to retain the customers and still stand out from competitors. So this research is very important for any family microenterprises, contributing valuable information in the difficult customer loyalty path. It also will benefit microentrepreneurs, helping them to understand that good service can be a competitive advantage, able to leverage their sales. Thus, the objective of this research lies in analyzing the current state of care of a family microenterprise, the garment branch, located in the city of Lupionópolis-PR and propose ways to make it more competitive by improving customer relations. As for methodology, the survey was conducted through qualitative approach, and the case study method as a driver and literature, combined with questionnaire and interview as data collection instrument. It was found with this analysis, the database implementation, post-sales, and training within the company is able to improve the relationship with customers, causing the company to obtain excellence in service, making it more competitive.
\end{abstract}

Keywords: Family Microenterprise. Marketing. Quality In Attendance . Loyalty.

\section{INTRODUÇÃO}

Uma das mais antigas formas de ser empresa é a familiar, que de acordo com Santos, (2008, p. 10) é "uma empresa onde a família detém o controle sobre os negócios, isto é, o valor mais importante da empresa é a família que em conjunto com seus integrantes determina o direito de sucessão nos cargos de direção". Sendo então a família responsável direta pela gestão da organização, mas do ponto de vista de Lodi
(1978, p.6) “O conceito de empresa familiar nasce geralmente com a segunda geração de dirigente [...]". Dessa maneira é possível perceber que na opinião desde autor a organização precisa passar por uma geração para que ela seja considerada empresa familiar.

$E$ as empresas familiares podem ser classificadas por tamanho tal como micro, pequena, média ou de grande porte. Sendo que destes tipos, a mais comum é a microempresa 
familiar, considerando que a maioria das organizações surgem de uma família, e em formato micro, assim é tão comum ver-se uma microempresa sendo administrada por familiares. E apesar de diferirem umas das outras as microempresas, principalmente, apresentam particularidades, desde sua estrutura que é pequena, até seus tributos e impostos que são diferenciados. Segundo Moraes (2005, p.13):

Enquadrar-se em uma das categorias de tamanho, especialmente de micro e pequeno porte, significa ter possibilidades de acesso aos benefícios previstos, envolvendo, geralmente, as áreas tributárias, crédito, exportações, simplificação burocrática na instalação [...].

Logo, cada empresa tem sua categoria e estrutura de tamanho, cada qual respeitando as leis que estão submetidas na modalidade de micro e pequena empresa, a simplificação e a desburocratização auxiliam e beneficiam estes negócios, tendo em vista que seu regime tributário é diferenciado e a Lei que garante esse regime é a Lei Complementar no 123/2006, no Cap. VI, Art. 12., onde fica instituído o Regime Especial Unificado de Arrecadação de Tributos e Contribuições devidos pelas Microempresas e Empresas de Pequeno Porte-Simples Nacional. (RECEITA FEDERAL DO BRASIL).

As leis especificas para as microempresas têm por finalidade auxiliar os pequenos empresários a terem seus empreendimentos regularizados e nas normas sem muita burocracia, já que as microempresas surgem na maioria dos casos com um pequeno capital individual ou por sócios, não sendo possível os fundadores pagarem altos impostos, igual às demais empresas, visto que na maioria das vezes se tem somente o dinheiro para pagar as despesas essenciais ao funcionamento, como: água, luz , aluguel e mercadorias ou matériaprima.

De acordo com a Lei 139/2011, Altera dispositivos da Lei complementar no 123, de 14 de dezembro de 2006:

Art. $\quad 3^{\circ}[\ldots]$ consideram-se microempresas ou empresas de pequeno porte a sociedade empresária, a sociedade simples, a empresa individual de responsabilidade limitada e o empresário a que se refere o art. 966 da Lei no 10.406 , de 10 de janeiro de 2002 (Código Civil), devidamente registrados no Registro de Empresas Mercantis ou no Registro Civil de Pessoas Jurídicas, conforme o caso, desde que:

I - no caso da microempresa, aufira, em cada anocalendário, receita bruta igual ou inferior a $\mathrm{R} \$ 360.000,00$ (trezentos e sessenta mil reais). (RECEITA FEDERAL DO BRASIL, 2014).

Pelo texto desta lei, é possível perceber que as micros e pequenas empresas possuem um faturamento máximo para enquadrar-se nesta modalidade e tem que estar regularizadas e devidamente registradas no órgão competente, para as microempresas, o faturamento anual não pode ultrapassar o valor de $R \$ 360.000,00$. E é esta modalidade de negócio o foco deste artigo, tendo em vista que as microempresas familiares correspondem a maioria das empresas brasileiras. E assim como as grandes, precisa ser competitiva para sobreviver.

Neste sentido, este artigo se justifica pela importância do tema, tendo em vista que as empresas precisam obter excelência no serviço, para manter-se nesse mercado e terá como beneficiados os microempresários, ajudando-os a compreender que um bom atendimento pode tornar-se um diferencial competitivo, capaz de alavancar as suas vendas e tornar a empresa conhecida. Sendo assim, o objetivo deste estudo é analisar o estado atual do atendimento de uma microempresa familiar, do ramo de confecções, situada na cidade de Lupionópolis-PR e propor formas de torná-la mais competitiva através do melhoramento das relações com o cliente.

E para tanto o marketing é essencial, como foi percebido a muitos anos, mais precisamente após a revolução Industrial, onde ocorreu um avanço na industrialização e as empresas passaram a experimentar uma competição mais acirrada.

Então as organizações sentiram a necessidade de elaborar estratégias para conquistar novos consumidores, já que os clientes passaram a ter o poder de decidir o que poderia proporcionar a melhor relação custo benefício, e como isso surgiu o marketing, que 
segundo Kotler (2002, p.30) "[...] é um processo social por meio do qual pessoas e grupos de pessoas obtêm aquilo que necessitam e o que desejam com a criação, oferta e livre negociação de produtos e serviços [...]". Em outras palavras, consiste na elaboração de estratégias, por parte das empresas, com objetivo de atrair o mercado consumidor, despertando interesse de consumo, podendo ser por necessidade ou desejo. Para Kotler e Keller (2009, p.4)

Pode-se considerar que sempre haverá a necessidade de vender. Mas o objetivo do marketing é tornar supérfluo o esforço de venda. O objetivo do marketing é conhecer e entender o cliente tão bem que o produto ou $\mathrm{o}$ serviço seja adequado a ele e se venda sozinho. Idealmente, o marketing deveria resultar em um cliente disposto a comprar. A única coisa necessária então seria tornar o produto ou o serviço disponível.

Entende-se que o marketing é uma ferramenta de extrema importância para auxiliar na venda dos produtos, e ajuda a ganhar espaço diante da concorrência, já que os clientes passam a comprar, sem que haja uma grande influência do vendedor, gerando assim resultado satisfatório para as organizações que se tornam mais competitivas.

Com um mercado mais competitivo as organizações, elaboram estratégias "por meio do marketing [...] a empresa é capaz de captar informações suficientes de seus clientes para compreender suas necessidades" (BARRETO; CRESCITELLI, 2013, p.2). Desta maneira este tipo de ferramenta se tornou importante para oferecer uma qualidade nos serviços, através dele é possível conhecer melhor as exigências dos consumidores, e, portanto proporcionar qualidade nos produtos e serviços.

Segundo Kotler e Keller (2006, p.145)

Qualidade é a totalidade dos atributos e características de um produto ou serviço que afetam sua capacidade de satisfazer necessidades declaradas ou implícitas. Essa é uma definição claramente voltada para o cliente. Podemos dizer que a empresa fornece qualidade sempre que seu produto ou serviço atende as expectativas do cliente ou as excede. Uma empresa que satisfaz a maioria das necessidades dos clientes durante o maior parte do tempo é denominada empresa de qualidade.

Neste sentindo a qualidade deve ser um fator de extrema importância para as empresas na hora de oferecer um produto ou no atendimento com os seus clientes. Hoje atender bem não é o suficiente para garantir vendas, é preciso exceder e surpreender de forma positiva, a clientela no momento que ela entra nas organizações, é fundamental que esta medida seja percebida, caso contrário, esta estratégia não trará benefícios para mesma.

Eventualmente um bom atendimento, vai muito além de recepcionar um cliente, mas também atender suas necessidades, exigências e reclamações. Para Kotler e Keller (2013, p. 84) “ [...] é importante também ser um defensor dos clientes e, na medida do possível, levá-los para dentro da empresa e entender seu ponto de vista". Portanto, é necessário atender as reclamações e sugestões dos consumidores, já que eles são essenciais para o futuro das organizações.

Outra característica da qualidade no atendimento é entender o que o cliente deseja, e atendê-lo com satisfação, [...] "objetivo é sempre exceder as expectativas de nossos clientes. Ao agir assim, tratamos cada um deles como se fosse o maior, e cuidamos de cada aspecto de nosso atendimento como se fosse o mais importante" (FRANCES; ROLAND BEE, 2003, p.16). Sendo assim, é possível notar a necessidade de que toda a organização esteja trabalhando em conjunto para atender bem a clientela, não só para oferecer produtos, mas ter um atendimento de qualidade de tal modo que o cliente possa se sentir encantado, mesmo que irá comprar um simples objeto ou que nem encontre o que deseja, mas possa se sentir valorizado pela empresa, e que volte outras vezes por saber que sempre será bem recepcionado.

Quando o consumidor tem suas expectativas correspondidas ou até mesmo excedidas, torna-se menos complexo alcançar sua satisfação, "o atendimento ao cliente também significa sair em sua busca, fazendo todo o possível para satisfazê-lo [...]". (GERSON, 2003, 
p.3), neste sentido é possível perceber que o cliente sente-se valorizado quando é tratado com algum diferencial na hora de realizar suas compras, que percebe que a empresa está tomando todas as atitudes necessárias para garantir a sua satisfação, e ainda acredita que essa conduta pode influenciar na longevidade da organização.

Segundo Kotler e Armstrong (2010, p.15), “[...] clientes encantados permanecem fiéis e falam favoravelmente sobre a empresa e seus produtos". Entende-se que os clientes satisfeitos, são capazes de promover a propaganda boca a boca, favorecendo a organização com um marketing positivo, contribuindo com o aumento da clientela.

Desta forma, é essencial encantar os clientes e para tanto, é preciso conhecer o perfil de cada um, sabendo assim das suas necessidades e anseios ao visitar a organização. Corroborando com o citado, segundo Cobra (1992, p.33) “É preciso que todas as áreas estejam voltadas para a descoberta das necessidades dos consumidores". Ocorrendo um dever que todos na organização estejam trabalhando na mesma sintonia, com objetivo para compreender o que os consumidores desejam e esperam da empresa, oferecendo a eles um atendimento de qualidade que está diferença possa ser percebida em favor da organização e principalmente dos clientes.

Segundo Gerson (2003, p.57)

Ter uma visão é vital para o sucesso dos serviços em qualquer organização. Ter visão é mais do que apenas a filosofia dos negócios. Ela deve ser a base da ética cultural corporativa. Todos devem acreditar e colocar em prática o aspecto visão para que sua empresa forneça excelente atendimento a clientes e mantenha por toda vida.

A partir do momento que as empresas possuem uma visão ampla de onde querem chegar e passam a tomar medidas cabíveis, com a finalidade que toda a organização passa trabalhar junto para alcançar este objetivo, e assim permanecer crescendo a cada ano, conquistando novos clientes e fidelizar os já existentes através de uma relação, onde a empresa atende a necessidade e desejos e oferece um atendimento de qualidade diferenciado dos seus concorrentes, ela se torna uma referência na hora da cliente efetuar suas compras.

No sentido em que a empresa se torna a preferência para os clientes, é sinal que conseguiu exceder todas as expectativas, "o segredo para gerar um grande nível de fidelidade é entregar um alto valor para o cliente" (KOTLER, KELLER, 2009, p.141). Percebe-se que a empresa necessita ser superior na proposta e benefícios que irá conceder ao seu público, gerando um nível alto de satisfação, capaz de promover sempre a compra e a recomendação da organização.

De acordo com Barreto e Crescitelli (2013, p.72) "o índice de satisfação vem sendo amplamente apontado como o principal antecedente da fidelização [...] a satisfação é condição necessário para que a fidelidade ocorra", desta maneira, o cliente se torna fiel a uma organização quando seu nível de satisfação está elevado, com o produto ou serviço que lhe é oferecido, onde ele vai se sentir comprometido, e percebe que mudar é inconveniente, por a empresa consegue atender tudo que ele necessita e deseja.

"O sucesso de uma organização de serviços muitas vezes depende da sua capacidade de desenvolver relações com os clientes e prestar serviço de qualidade" (CHURCHILL JUNIOR; PETER 2000 apud RAZZOLINI FILHO, 2010, p.100). Portanto, um dos meios para as empresas alcançarem o sucesso que tanto almeja, o caminho a seguir e investir, é um bom atendimento, aliado a extrema qualidade dos produtos ofertados, buscando assim atender a todos os anseios dos consumidores, fazendo com que a empresa tenha uma ampla clientela de forma fiel.

Para alcançar à fidelização a empresa precisa percorrer um longo caminho, s, é preciso atrair e fidelizar clientes, e para tanto, se faz necessário estudar alguns comportamentos ou influencias que levam ao consumo.

Para Gade (1998, p.1):

O comportamento de consumo é definido como comportamento de procura, busca, compra, uso e avaliação de produtos e serviços para satisfazer necessidade. comportamento do consumidor são as atividades físicas, mentais e emocionais 
realizadas na seleção, compra e uso de produtos e serviços para satisfação de necessidade e desejos.

Desta maneira, quando a empresa busca conhecer melhor os seus clientes no momento da procura pelos produtos, isso se faz através da avaliação do seu comportamento no instante da aquisição, ela pode trazer vantagens e colaborar com o aumento das vendas, compreendendo, o seus pensamentos e ações no decorrer dessa análise, para que assim ela conheça mais de seu público do que as suas concorrentes, no sentido de oferecer o que realmente cada cliente procura e cada vez mais perceber as suas necessidades e desejos.

Neste sentido, é interessante realizar um "processo de sondagem ou de observação e análise das necessidades e dos desejos do segmento focado [...]" (PAIXÃO, 2012 p. 20), com a finalidade de "[...] compreendermos o processo de compra e as atitudes dos clientes no momento do consumo." (PAIXÃO, 2012, p. 20). Ou seja, na hora da compra, a observação se torna um fator muito importante, em que todos os colaboradores precisam atentarem nas atitudes de cada cliente, pois os mesmos são a chave do negócio, e futuramente saber o que mais se encaixa com seu perfil.

Mas, além disso, é importante ressaltar que as escolhas e preferências de cada indivíduo estão diretamente relacionadas com o ambiente que nasceram e cresceram como afirma, Paixão (2012, p. 23) "[...] os aspectos relacionados às nossas preferencias, às nossas percepções e aos nossos comportamentos estão impregnados das influencias que recebemos da sociedade em que crescemos e vivemos ou são, de alguma forma, moldados por elas". Sendo assim, é possível notar que as pessoas são influenciadas a todo momento, seja em casa, no grupo de amigos, na escola, e assim vão sendo modeladas para adquirirem um perfil de consumo.

E essas influências nunca param, pois o mundo está em constante mudança, assim como cada pessoa. Para que seja possível compreender um pouco mais a respeito, vale destacar que existem diversos fatores que influenciam no comportamento dos clientes na hora da compra e consumo. Pode-se citar alguns, como fatores externos: culturais, demográficos, sociais, familiares, econômicos, e de marketing (que é um fator interno da organização). Nos próximos parágrafos são apresentados, cada um destes fatores, iniciando-se por "cultura".

Que para Samara e Morsch (2005 p. 55) "cultura pode ser definida como a acumulação de valores, crenças, costumes, conhecimento [...]". Portanto, o hábito de comprar tal coisa vem da cultura em que está inserida, então o consumo e a procura são pelos produtos que se identificam com as crenças, trazendo uma identidade de cada indivíduo.

Outro fator influenciador é o demográfico, que Gianesi e Corrêa (2008 p. 68) dizem que "fatores demográficos são como idade, ocupação e condição econômica", sendo assim no fator demográfico o consumidor é influenciado pelo consumo do seu grupo, seja ele, familiar, da mesma idade, ou classe social, onde são determinados pela região onde se vivem.

Já os fatores sociais, segundo Gade, (1998, p. 177) “[...] são então padrões de comportamento esperados para o indivíduo que ocupa determinada posição no grupo. À medida em que a sociedade se modifica, os papéis sociais também o fazem [...]". Deste modo o fator social influencia através do grupo que se relacionam na convivência com a sociedade, trazendo um pouco para si o que o mundo ao seu redor oferece, assim podendo ser modificada, através das mudanças que ocorre no ambiente em que se vive. Para Kotler e Armstrong, (2003, p. 124) "os membros da família podem influenciar bastante o comportamento do comprador. A família é a mais importante organização de compra de produto de consumo da sociedade[...]". Diante disso, uma das influencias mais significativas é a do convívio familiar é lá que adquire-se a maioria dos comportamentos de compra, uma vez que é uma influência primaria, onde obtém-se o primeiro contato afetivo.

Outro fator a ser considerado é o econômico, de acordo com Kotler, (2000, p. 167) no fator econômico "o poder de compra em uma economia depende da renda, dos preços, da poupança, do endividamento e da disponibilidade de crédito." Neste sentido, as classes econômicas geram as divisões de rendas, onde cada uma tem um poder de compra diferente; os que tiverem um maior poder aquisitivo consumirão produtos mais caros com frequência, por isso a organização precisa definir seu público alvo para estabelecer os preços, e a disponibilidade de crédito. 
E por fim, um dos fatores mais conhecidos, o "marketing", para Paixão, (2012, p. 30) fatores de marketing "[...] as estratégias de produto, o preço, a promoção, o ponto de vendas e as pessoas-relacionamento com os públicos". Portanto, esse fator depende de como as empresas irão atrair a atenção dos seus consumidores, seja elas pela qualidade e característica do produto; o preço acessível, prazo de pagamento ou somente ao um grupo com um poder aquisitivo; realizar promoções para dar valor ao seu produto, força de vendas; a localização da empresa; e a relação entre cliente e colaboradores através do atendimento de qualidade.

"As atividades de marketing também são potenciais influenciadores no processo de compra, por intermédio das variáveis do composto mercadológico: produto, preço, ponto e promoção". (HONORATO, 2004, p. 135) É através desses quatro - $4 p^{\prime} s$, como são comumente conhecidos - que são tomadas as decisões internas do marketing da empresa, podendo diferenciar de seus concorrentes. Seduzindo os consumidores a comprarem mais, seja pela ótima promoção, propagandas, adotando as tendências que estão na moda para a empresa, estimulando e influenciando na hora do consumo.

Pode-se então destacar cada um dos $4 p$ 's: produto que envolve as marcas, modificações e embalagens dos produtos oferecidos ao cliente para satisfazer suas necessidades e desejos; o preço seria quanto nosso cliente está disposto a pagar por aquele produto, através de sua situação econômica para Ihe trazer benefícios, não somente o lucro para a empresa; a promoção engloba as propagandas da sua loja juntamente com os produtos promocionais, trazendo uma comunicação e relação com seu público; e o ponto de vendas, onde é a localização da loja ou distribuição do produto, e o armazenamento do mesmo, que a organização conquista seus clientes (GADE, 1998). Sendo assim, é possível notar que o cliente é fortemente influenciado pelo ambiente interno da organização, o profissional de marketing utiliza-se desses $4 p$ 's para gerar estímulos aos consumidores, fazendo com que eles sintam a necessidade de comprar algo mesmo que não esteja necessitando no momento e sim por um desejo.

Sendo mais conhecidas, essas ferramentas, como o mix de marketing, que significa exatamente o "[...] conjunto de variáveis controláveis que a empresa pode utilizar para influenciar a resposta dos consumidores". (HONORATO, 2004, p.06) Sendo assim, por meio dessas ações é possível as empresas aumentarem a demanda pelos seus produtos e influenciar seus clientes no processo de escolha destes. Estas variáveis a empresa pode controlar para atender seu público e conquistá-lo, de maneira a influencia-los sempre a comprar no seu estabelecimento, por estarem preocupados não tão somente nos lucros, mas também com as suas necessidades e desejos, pois através do mix de marketing a empresa conhece seu público induzindo-os e agregando valor a suas compras.

Como afirma Honorato (2004, p.06) "Os consumidores não compram coisas, e sim soluções para seus problemas". Com isso, o mix de marketing ajuda a empresa a atrair os clientes para dentro do estabelecimento e soluciona os problemas dos consumidores sejam eles uma necessidade ou desejo, através dos produtos que podem facilitar no dia a dia, cada produto ou serviço é especifico para um segmento ou grupo de pessoas, que sempre estão em constante mudanças e buscando alcançar a tecnologia e a moda.

Com a globalização e a tecnologia avançada, a organização tem que sempre estar atualizando o seus produtos e serviços como afirma Paixão (2012, p. 51) "com a velocidade das informações e das inovações nos produtos e serviços, os consumidores estão bem mais seletivos e exigentes. Esse é um dos principais motivos pelos quais as empresas precisam conhecê-los cada vez mais". Contudo, consumidores exigentes precisam de empresas eficientes que sempre estão à disposição com opções de produtos com qualidade e atendimento eficaz para vendê-los, pois não adiante a empresa obter os melhores produtos se eles não são vendidos de maneira adequada. Portando, os colaborados das organizações bem preparados e treinados conseguem atender com qualidade e oferece as melhores escolhas para cada necessidade dos seus clientes, influenciando-os para comprarem sempre seus produtos e serviços.

Segundo Kotler e Armstrong (2007, p. 16) pode-se ainda "[...]treinar os funcionários para fazer vendas cruzadas e vendas incrementais com o intuito de negociar mais produtos e serviços com os clientes existentes" Desta maneira entende-se que a organização precisa treinar 
seus funcionários e disponibilizar a eles as informações e a análise do comportamento dos seus clientes, pois quem está à frente e tem contado é o vendedor, por meio deste conhecimento, os colaboradores podem oferecer outros produtos além daqueles que o cliente buscou comprar, criando um tipo de combinação e agregando valor aos outros produtos, fazendo com que ele compre mais do que inicialmente tinha previsto.

Assim como diz Frances e Bee (2002, p. 23) "é muito difícil oferecer um bom atendimento aos clientes a menos que se saiba exatamente quem eles são". Por isso se dá a importância de conhecer seus clientes e encontrar formas para retê-los, só assim a empresa pode oferecer um atendimento de qualidade, e os produtos para cada tipo de necessidade.

Para que isso aconteça a organização precisa antes de tudo disponibilizar essas informações obtidas dos clientes para os próprios vendedores, facilitando no atendimento, e treinando-os para oferecer um atendimento de qualidade. Para Hooley, Saunders e Piercy (2005. p. 338):

As empresas precisam, além de se comprometer com um padrão superior em suas estratégias, implantar sistemas que permitam a seus funcionários prestar esse serviço superior aos clientes (Payne, 1993) [...] os funcionários precisam reconhecer a importância da prestação de serviços ao cliente e estar comprometidos em faze-los.

A qualidade no atendimento se tona uma ferramenta na decisão de compra do cliente, pois com as informações adquiridas dos clientes, os funcionários conseguirão atendê-los como eles realmente gostam, uma vez que cada um tem um jeito de se comunicar e interagir com o outro, os clientes extrovertidos, é necessária uma maior comunicação e interação, já os clientes tímidos não gostam de muitas perguntas, sendo objetivo na sua compra. Os funcionários comprometidos com a importância do atendimento e prestação de serviço oferece-os com qualidade, desta forma, o cliente não quer simplesmente uma mercadoria, ele sente a necessidade de ser bem recebido em qualquer lugar que ele entra ou esteja, assim fortalecendo um bom relacionamento entre ambos e o consumidor sempre volte a sua empresa.

Como ainda cita os autores Frances e Bee (2002, p. 35) " oferecer excelência em atendimento ao cliente depende de termos as informações corretas.", para tanto as informações que a empresa coleta dos clientes tem que ser usadas de maneira adequada, onde possa trazer benefícios e crescimento das vendas, quando mais se conhece seus gostos e hábitos, menos a chance de oferecer produtos errados, para dar mais ênfase de como a qualidade no atendimento e os dados sobre a clientela pode contribuir na retenção dos mesmos.

Sendo assim, se torna importante a realização de pesquisa com os clientes para melhor entender sua necessidade e desejos, adotando medidas indispensáveis para gerar a satisfação e aperfeiçoar o relacionamento entre as partes, pois ao perceber que a empresa esta mudando para melhor atender, por menor que sejam as mudanças podem gerar uma grande satisfação por parte da clientela, tornando assim uma relação duradoura, diminuindo o risco de perder os consumidores. Sua perda poderá causar um enorme prejuízo, e qualquer mudança dentro da organização com o objetivo de satisfazer será menos oneroso. De acordo com Samara e Morsch (2005, p.213)

No ambiente competitivo contemporâneo, o processo de satisfação é especialmente importante para os sábios profissionais de marketing que compreendem que, na era do relacionamento, o sucesso não está em vender, mas sim em moldar um relacionamento duradouro com o consumidor de modo que ele continue a comprar seus produtos no futuro e não ceda aos apelos da concorrência.

Neste sentindo a empresa não pode só pensar em vender de qualquer maneira, incentivar seus clientes a comprar algo que ele não ira usar, mas oferecer a ele algo que realmente seja do seu agrado, e criar assim um elo entre ambos, pois é satisfatório ter um cliente fiel, que leve o nome da empresa por onde passa, do que efetuar uma venda de qualquer jeito, de 
modo errado e com consequência de perdê-lo para sempre.

O importante não é só efetuar as vendas, mas é essencial manter um diálogo com o cliente após aquisição de algum produto e entender se esta compra o deixou satisfeito, "[...] por meio de feedback dos clientes, as empresas possam encontrar soluções e meios para otimizar os seus produtos, processos e serviços". (SAMARA, 2005, p.212). No entanto torna-se um diferencial competitivo, acompanhar o consumidor após as compras (o conhecido "pós-venda") e assim compreender se a compra foi satisfatória, se o atendimento oferecido foi de qualidade. Com essas medidas cabíveis a organização se aproxima mais do seu consumidor, podendo assim tomar decisões para melhorar as atividades desenvolvidas.

Além de manter um bom relacionamento, hoje a tecnologia tornou-se uma ferramenta de suma importância para as organizações. O CRM (Customer Relationship Management, traduzida para língua portuguesa, Gestão de Relacionamento com o Cliente) é um dos softwares mais conhecidos e se tornou uma ferramenta para auxiliar em um melhor relacionamento com os consumidores.

De acordo com Lovelock e Wirtz (2006, p.316)

[...] CRM bem implementados
podem Ihe oferecer uma
interface unificada, o que
significa que, em causa
transação, os detalhes
relevantes de uma conta, o
conhecimentor das
preferências do cliente e de
suas transações anteriores, ou
o histórico de um problema
de serviço estão ao alcance
dos dados da pessoa que o
está atendendo. Isso pode
resultar em grande melhoria
no serviço.

Neste sentido, podemos afirmar que o CRM é uma fundamental ferramenta para se realizar o estudo aprofundado da carteira de clientes, já que através dele existe a possibilidade de conhecer um pouco mais sobre o público alvo, identificar o potencial, saber quais são suas preferências, o que estão habituados a comprar, a partir deste ponto torna-se menos complexo elaborar estratégias para atrair e trazê-los para dentro da organização. Com esses dados podem ser elaboradas novas medidas para atrair o consumidor, com promoções, cartão fidelização, bônus entre outros, "incentivos que oferecem recompensas baseadas na frequência ou no valor da compra ou na combinação dos dois representam um nível básico de vínculo com o cliente" (LOVELOCK; WIRTZ, 2006, p.310). Sendo assim, esses benefícios constituem uma maneira de se criar um vínculo com os consumidores, numa tentativa de torná-lo fiéis, com um software que todos dentro da organização podem ter acesso aos dados, torna-se mais fácil identificar as preferências da clientela. Esta ferramenta vai auxiliar na tomada de decisão, só que sua instalação não é garantia de sucesso, mas sim um diferencial.

Segundo Ramez e Shamkant (2001, p.3):

Um banco de dados é uma coleção de dados relacionados. Com dados, queremos dizer fatos conhecidos que podem ser registrados e possuem significados implícitos. Por exemplo, considere os nomes, números de telefone $\mathrm{e}$ endereços das pessoas que você conhece.

Entende-se que o CRM possui relevante importância por ser tratar de uma ferramenta onde se pode armazenar todas as informações sobre os seus clientes, de forma a contribuir positivamente na tomada de decisão, já que o banco de dados permite um maior conhecimento sobre a clientela, permitindo assim um melhor relacionamento e satisfação, já que a cada dia a empresa, tem que ser aperfeiçoar para melhor atender.

Conhecendo melhor o perfil dos clientes, a empresa possui uma vantagem perante seus concorrentes, para oferecer um atendimento de qualidade que é essencial para conseguir encantar e fidelizar os clientes, "[..] a fidelização está relacionada não apenas com a recompra, mas também com a preferência pela marca" (BARRETO, 2013, p. 72). Neste sentido é possível percebe quando o cliente percebe a qualidade em um produto ou no atendimento ele volta à comprar e acaba se tornando um cliente fiel, fazendo com que a organização consiga se destacar dos adversários, no mercado que esta cada vez mais competitivo e difícil de se manter.

A partir do exposto, entende-se que para a empresa obter sucesso nas suas atividades, 
tornar-se mais competitiva e atingir a fidelização dos seus clientes, algumas ferramentas e ações são de extrema importância, como os princípios da organização, visão, missão e valores, CRM, banco de dados sempre atualizado, feedback (pós venda), avaliação para saber a opinião que a clientela tem sobre a empresa, ter alguma bonificações ou premiações para os consumidores e os vendedores junto a equipe sempre mostrarem-se atenciosos na hora de efetuar uma venda, essas ferramentas e ações auxiliam na tomada de decisão, e oferecem mais qualidade na hora de concretizar as vendas, passando assim confiança, para se manter no mercado, fidelizando os clientes existente e buscando oportunidades de conquistar novos.

\section{ASPECTOS METODOLÓGICOS}

Uma parte importante da pesquisa é a identificação da metodologia, que precisa estar adequada aos objetivos do estudo. Neste sentido, o presente artigo foi realizado através de uma abordagem qualitativa, tendo o estudo de caso como método condutor; e a pesquisa bibliográfica aliada a entrevista e ao questionário como instrumentos de coleta de dados. A seguir tem-se o detalhamento destes métodos.

Iniciando pela abordagem qualitativa, que de acordo com Mascarenhas (2012, p.46) é utilizada "[...] quando queremos descrever nosso objeto de estudo com mais profundidade". Ou seja, é subjetivo e permite a analise detalhada do foco de estudo.

Outro método utilizado foi o estudo de caso que conforme Barros e Lehfeld (apud CHIZOTTI, 2007, p. 112) é "[...] uma modalidade de estudo nas ciências sociais, que se volta á coleta e ao registro de informações sobre um ou vários casos particularizados [...]". Neste sentido o estudo de caso consiste em informações coletadas, para casos que serão estudados e analisados, este método foi necessário para o detalhamento desta pesquisa, com um estudo mais profundo e dedicado das informações.

Quantos aos instrumentos de coleta de dados foram utilizados "a pesquisa bibliográfica é que se efetua tentando-se resolver um problema ou adquirir conhecimento a partir do emprego predominante de informações advinhas de material gráfico, sonoro e informatizado". (BARROS; LEHFELD, 2007, p.85). Para a realização de qualquer pesquisa cientifica é necessário fundamentar através de materiais encontrados em livros, artigos, revistas cientificas, com o objetivo de analisar e adquirir conteúdo relacionado com o tema abordado. E como forma de complementar a teoria, foi empregada a entrevista que "[...] não é uma simples conversa. É uma conversa orientada para um objetivo definido: recolher, por meio de interrogatório do informante, dados para a pesquisa". (CERVO; BERVIAN; SILVA, 2007, p. 50). Neste sentido foi adquirido conteúdo, através desta, com a intenção de encontrar mais informações relacionadas com a empresa estudada, sendo assim a entrevista serviu para complementar a teoria. Ela foi realizada com o fundador da loja, no dia 04 de setembro de 2014.

E por fim, o ultimo instrumento utilizado: o questionário, que para Cervo, Bervian e Silva $(2007$, p.53) "[...] é uma forma mais usada para coletar dados, pois possibilita medir com mais exatidão o que se deseja. Em geral a palavra questionário refere-se a um meio de obter respostas as questões por uma fórmula que o próprio informante preenche".

Sendo assim, este trabalho tem embasamento advindo também da aplicação de questionário, que se fez com a finalidade de conhecer o perfil e opinião sobre o objeto de estudo. Os questionários foram aplicados no dia 04 de setembro de 2014, para 24 clientes da loja.

\subsection{Universo da Pesquisa}

O universo que esta pesquisa se propôs a analisar, envolveu o fundador de uma loja de confecções, situada na cidade de Lupionópolis$\mathrm{PR}$, bem como vinte e quatro clientes da referida empresa, com o objetivo de adquirir mais informações a respeito do negócio, com destaque para o atendimento. Sendo que se utilizou como critério para seleção dos clientes pesquisados: os que efetuaram compras no dia da realização da pesquisa e clientes que compram frequentemente.

\section{ANÁLISE E DISCUSSÃO DOS DADOS}

A forma escolhida para analisar o estado atual do atendimento de uma microempresa familiar, do ramo de confecções, situada na cidade de Lupionópolis-PR e propor formas de torná-la mais competitiva através do melhoramento das relações com o cliente, foi contextualizar a teoria (através de livros, artigos, sites e leis), com a prática, por meio de entrevista com o proprietário e de aplicação de questionário a alguns clientes da organização, objeto deste estudo. 
Buscou-se analisar na entrevista a concepção do fundador em relação a qualidade no atendimento prestado por seus funcionários e qual a importância deste assunto. Já com os clientes buscou-se saber se 0 atendimento prestado a eles é realmente satisfatório, capaz de fazê-los fiéis a empresa.

Este levantamento e análise permitiram cruzar as informações, com o objetivo de solucionar o problema deste estudo, verificando qual o estado atual do atendimento de uma microempresa familiar, do ramo de confecções, situada na cidade de Lupionópolis-PR, e o que pode ser feito no aspecto de melhoramento das relações com o cliente para torná-la mais competitiva?

Inquirindo as respostas do proprietário da empresa é possível perceber que a qualidade no atendimento é de suma importância e faz parte da vivencia da organização "sempre cobramos de nossos funcionários a darem o melhor de si, na hora de atender um cliente e ter a consciência e perguntar a si mesmo se é o tipo de atendimento que gostariam de receber em outras lojas". De maneira objetiva é possível percebe que oferecer um atendimento de qualidade é uma prioridade, incentivada entre os funcionários da organização, com a finalidade de conquistar os clientes.

Ideia esta que vai de encontro ao que e Kotler e Armstrong (2010, p.15) difundem “[...]

Gráfico 1. Nível de satisfação dos clientes da empresa clientes encantados permanecem fiéis e falam favoravelmente sobre a empresa e seus produtos" deste modo é possível relacionar as ideias do fundador da organização com a expressada pelos autores, um atendimento de qualidade é capaz de encantar os clientes e pode torna-los fiéis e assim contribuir para o crescimento da organização.

Ainda sobre a visão que o proprietário tem sobre o atendimento: "Quando o cliente chega a loja, ele deve sentir que notamos a sua presença, com bom dia, boa tarde, chamando pelo nome, mas tem que haver sinceridade nas palavras, porque temos que trata-los da mesma maneira na rua, na igreja, ou em qualquer lugar que o encontramos".

Corroborando de tal modo com Poser, (2005, p, 24) segundo o autor "as nossas posturas, gestos, feições e especialmente o olhar são fatores determinantes para que possamos expressar nossas emoções. Mesmo sem a emissão de qualquer palavra". Neste sentindo, o que foi dito reforça a fala do autor, é essencial que as palavras e gestos sejam de forma sincera e clara, passando para o cliente sempre disposição e vontade na hora do atendimento.

Evidenciando que na empresa objeto de estudo, a qualidade no atendimento é uma preocupação constante, e que tem gerado bons frutos, conforme evidencia o gráfico a seguir:

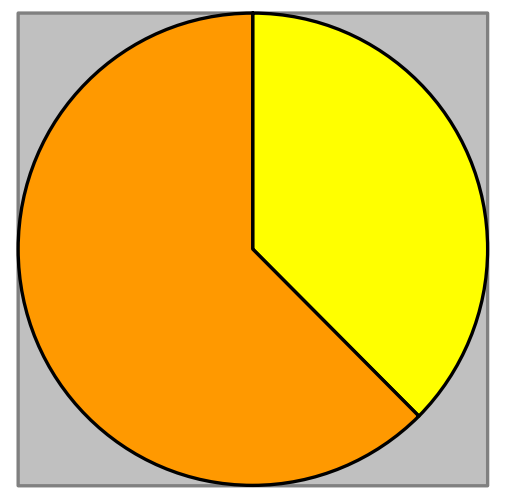

\begin{tabular}{|l|}
$\square$ entre 0 e 4 \\
$\square$ entre 5 e 7 \\
$\square$ entre 8 e 10
\end{tabular}

Fonte: elaborado pelas pesquisadoras.

Em uma escala de 0 a 10, nenhum cliente atribuiu nota menor do que 5 ao atendimento prestado pela empresa, 37,5\% deu nota entre 5 e 7 e o restante, $62,5 \%$ dos entrevistados atribuiu nota entre 8 e 10 para o atendimento recebido na empresa. E como "o sucesso de uma organização de serviços muitas vezes depende da sua capacidade de desenvolver relações com os clientes e prestar serviço de qualidade" 
(CHURCHILL JÚNIOR; PETER 2000 apud RAZZOLINI FILHO, 2010, p.100) fica evidente que o estado atual do atendimento da organização objeto de estudo é considerado bom, porém, pode se tornar ainda melhor, já que a nota dez (maior, na escada) não foi a única mencionada.

E considerando que $50 \%$ dos consumidores disseram que deixariam de efetuar suas compras em caso de haver mal atendimento, observa-se que sua qualidade é de sua importância para o crescimento da organização. Assim como ressalta Bee e Frances (1995, p13) “[...] ao perder um cliente, geralmente não se perde somente a venda, mas potencialmente uma vida inteira de vendas", percebendo a necessidade de cuidar de todos os clientes como únicos, pois um mau atendimento, como mostra a pesquisa, faz o cliente deixar de comprar, podendo ocorrer inclusive, a sua migração para a concorrência.

Entre os fatores citados pelos clientes como influenciadores da sua decisão de compra tem-se o bom atendimento como principal, como é possível visualizar no gráfico a seguir:

Gráfico 2. Influenciadores da decisão de compra dos clientes da empresa

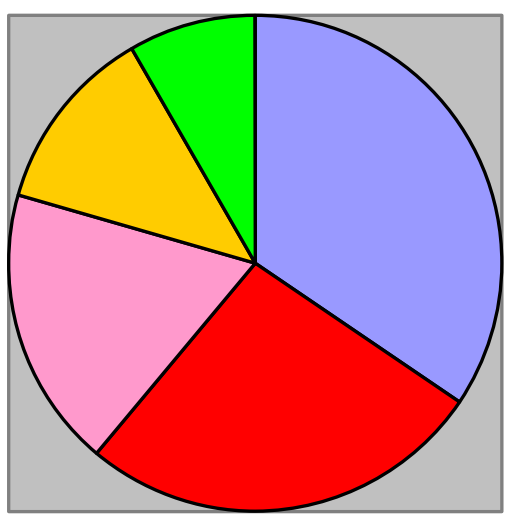

\begin{tabular}{|l|}
$\square$ bom atendimento \\
$\square$ Preço \\
$\square$ qualidade dos \\
produtos \\
$\square$ localização \\
$\square$ hábito e \\
promoção
\end{tabular}

Fonte: elaborado pelas pesquisadoras.

O bom atendimento foi mencionado por $70 \%$ dos clientes como influenciador da sua decisão de compra; seguido pelo preço, citado por $54,17 \%$; enquanto $37,50 \%$ mencionaram a qualidade do produto; $25 \%$ citaram a fácil localização da empresa e $16,67 \%$ hábito e promoção.

Reforçando ideia do autor Honorato (2004, p.135) “As atividades de marketing também são potenciais influenciadores no processo de compra, por intermédio das variáveis do composto mercadológico: produto, preço, ponto e promoção". De acordo com as ideias do autor e as opiniões dos clientes, vê-se a necessidade de estratégias internas dentro da organização, pois com o marketing pode-se induzir os clientes a comprarem na sua loja e assim conquistando-os, seja pela diversificação dos produtos, para satisfazer suas necessidades e desejos; o preço seria competitivo; a promoção que engloba as propagandas e os produtos promocionais, trazendo uma comunicação e relação com seu público; e o ponto de venda, que é a localização da loja.

Porém, é preciso destacar que apesar do atendimento ter recebido, em sua maioria, nota entre 8 e 10, uma porcentagem significativa de $45,83 \%$ dos clientes acredita que o atendimento oferecido pela empresa ainda deve-ser melhorado para sua maior satisfação ao realizar suas compras.

Esta descrição vem de encontro com as ideias difundidas por Barreto e Crescitelli (2013, p.72) segundo eles "o índice de satisfação vem sendo amplamente apontado como o principal antecedente da fidelização [...]" Com isso, constata-se que para os clientes serem fieis a uma empresa eles precisam estar satisfeitos, isso significa que cada vez mais é necessário que a organização em estudo procure alternativas para satisfazer esses consumidores.

Uma forma de contribuir para oferecer um atendimento de qualidade é a empresa propor aos colaboradores treinamentos. 
Segundo o proprietário "procuramos passar para o funcionário que o cliente é em primeiro lugar, ele que paga o salário de cada um. Atualmente estamos em falta com os treinamentos". De forma sincera nota-se que a empresa procura passar aos seus colaboradores que $o$ atendimento de qualidade é essencial para satisfazer o cliente, mas que atualmente não foi realizada nenhuma forma de treinamento para melhorar as atividades do dia a dia da organização.

Assim como diz Kotler e Armstrong (2007, p. 16) "[...] treinar os funcionários para fazer vendas cruzadas e vendas incrementais com o intuito de negociar mais produtos e serviços com os clientes existentes". Sendo assim, é possível perceber que o treinamento é essencial para melhorar as atividades da organização, e o proprietário sabe disso, mais reconhece que no atual momento a empresa não oferece este tipo de auxilio aos seus colaboradores.

Outra alternativa interessante para melhorar o relacionamento com os clientes, e que atualmente a empresa não possui, é o banco de dados, que segundo Ramez e Shamkant (2001, p.3) “Um banco de dados é uma coleção de dados relacionados. Com dados, queremos dizer fatos conhecidos que podem ser registrados e possuem significados implícitos". Neste sentido, pode-se obter as informações sobre os clientes, através de um banco de dados sempre atualizado, permitindo um conhecimento melhor do público e identificando suas preferências. E o pós venda pode ser um grande aliado neste quesito também.

Nota-se então, que o próprio proprietário tem conhecimento da importância de um banco de dados na empresa, mas até o momento a mesma não possui essa ferramenta para acompanhar o histórico de sua clientela. Segundo ele: "Deveria ser regra, mas nem sempre acontece, por falha da equipe ou mesmo por falta de cobrança dos proprietários". Desta forma a empresa deixa de ter uma ferramenta essencial, capaz de permitir um melhor conhecimento sobre sua clientela e assim melhorando a relação entre ambos.

Para tanto, os clientes garantem que são fieis a empresa quando os vendedores são atenciosos (95,83\%); e sempre oferece os produtos que você gosta $(79,17 \%)$. Sendo assim, percebe-se a importância de conhecer os consumidores para que os colaboradores possam oferece os produtos que the agradem, como cita os autores Frances e Bee (2002, p. 35) "oferecer excelência em atendimento ao cliente depende de termos as informações corretas". Com essa afirmação fica claro a importância de se conhecer e obter informações dos parceiros da organização, porque são eles que alavancam o crescimento da mesma.

E ainda concordando com a fala do proprietário: "Sempre acreditei, é comprovado em pesquisa onde o atendimento atinge a excelência por todas as esferas, ou seja, do patrão, gerente e funcionários a empresa tem tudo para progredir. A empresa não consegue fidelizar seu cliente só com promoção, preços, ótima localização, visual bonito, somente com atendimento superando a expectativa do cliente, é que fidelizamos os clientes mais isso tem que ser todos os dias, horas e minutos, têm que ser diferente da concorrência".

Neste sentido, um bom atendimento é peça chave para qualquer empresa que tenha como objetivo de crescer, conquistar e fidelizar seus clientes e assim ter um diferencial competitivo.

Portando, as reflexões propostas nesta seção, possibilitam inferir que apesar do estado atual do atendimento da empresa em estudo ser considerado bom, os clientes estão cada vez mais exigentes, e com isso, para manter-se competitiva é necessário melhorar alguns aspectos. $\mathrm{E}$ as ferramentas de marketing propostas para tanto são: treinamento, banco de dados e pós venda.

\section{CONSIDERAÇÕES FINAIS}

Este estudo se propôs a analisar o estado atual do atendimento de uma microempresa familiar, do ramo de confecções, situada na cidade de Lupionópolis-PR, e o que pode ser feito no aspecto de melhoramento das relações com o cliente para torná-la mais competitiva.

E ao longo das seções, foi possível confirmar que um dos fatores chaves para 0 crescimento da empresa, é o atendimento, de modo geral, a qualidade do mesmo define se os clientes estão satisfeitos ou não com a empresa. E percebeu-se que a organização estudada tem consciência de tal importância, o estado atual do atendimento prestado aos consumidores é considerado bom.

Porém, constatou-se também que os clientes estão cada dia mais exigentes, que é muito importante conhecê-los e saber suas 
preferências, gostos e hábitos, o acharam da aquisição, e da empresa ao realizar suas compras. Diante disso, conclui-se que 0 atendimento da empresa analisada é bom, mas precisa ser melhorado para suprir as exigências dos consumidores atuais, e o treinamento, o pós venda e o banco de dados são propostos como forma de melhorar o relacionamento com os clientes tornando a empresa mais competitiva.

Por fim é essencial destacar que apesar do comprometimento e empenho que buscou-se desenvolver para concretização deste estudo, tem-se a certeza de que ele corresponde a uma pequena parte, inserida dentro de um assunto tão amplo e importante para a atualidade. Neste sentido, acredita-se que correlacionar os resultados deste artigo com o market share econômico da empresa analisada pode ser um caminho para continuidade e aprofundamento das questões aqui estudadas, tendo em vista que não foram mencionados nesta pesquisa.

Desta maneira, espera-se que esta pesquisa contribua para novas descobertas e auxilie as microempresas a tornarem-se mais competitivas, através da melhoria do relacionamento com os clientes.

\section{REFERÊNCIAS}

BARRETO, I.F.; CRESCITELLI, E. Marketing de relacionamento: Como implantar e avaliar resultados. São Paulo, Pearson Education do Brasil, 2013.

BARROS, A. J. S.; LEHFELD, N. A. S. Fundamentos de metodologia cientifica. SãoPaulo: Pearson Education do Brasil, 2007.

BEE, R.; FRANCES. Fidelizar o cliente. 6. ed. São Paulo: Nobel, 2003.

BRASIL. Receita Federal. Lei Complementar no 123, de 14 de dezembro de 2006. Disponível em: <http://www.receita.fazenda.gov.br/Legislacao/L eisComplementares/ 2006/leicp123.htm> Acesso em: 03 maio 2014.

BRASIL. Receita Federal. Lei Complementar no 139, de 10 de novembro de 2011. Disponível em <http://www.receita.fazenda.gov.br/Legislacao/L eisComplementares /2011/leicp139.htm> Acesso em: 03 maio 2014.

CERVO, A. L.; BERVIAN, CERVO, A. L. P. A.; SILVA, R. Metodologia Científica. 6. ed. São Paulo: Pearson Prentice, 2007.

COBRA, M. Administração de marketing. 2. ed. São Paulo: Atlas, 1992.

FRANCES; BEE, R. Fidelizar o cliente. São Paulo: Nobel, 2002.
GADE, C. Psicologia do consumidor e da Propaganda. São Paulo: EPU, 1998.

GERSON, R.F., A excelência no atendimento a clientes: mantendo seus clientes por toda a vida. Rio de janeiro: Qualitumark, 2003.

GIANESI, I. G. N.; CORRÊA. Administração estratégica de serviços: operações para a satisfação do cliente. São Paulo: Atlas, 2008.

HEMZO, M.A.; LOVELOCK, C.; WIRTZ, J. Marketing de serviços: Pessoas, tecnologias e estratégia. Tradução de Yamamoto, S.M, 7 ed. São Paulo: Pearson Prentice Hall 2011.

HONORATO, G. Conhecendo o marketing. Barueri: Manole, 2004. Disponível em: <http://unoeste.bv3.digitalpages.com.br/users/p ublications/9788520417218/pages/7> Acesso em: 22 jul. 2014

HOOLEY, G. J.; SAUNDERS, J. A.; PIERCY, N. F. Estratégia de marketing e posicionamento competitivo. 3. ed. São Paulo: Pearson Prentice Hall, 2005.

KOTLER, P. Administração de marketing: a edição do novo milênio. São Paulo: Prentice Hall, 2000.

KOTLER, P.; ARMSTRONG, G. Princípios de marketing. 9.ed. São Paulo: Prentice Hall, 2003.

KELLER, L. K. ; KOTLER, P. Marketing essencial. 5. ed. São Paulo: Pearson education do Brasil,, 2013. KOTLER, P. Administração de marketing: A edição do novo milênio. São Paulo: Pearson Education Brasil, 2002.

KOTLER, P.; ARMSTRONG, G. Princípios de marketing. 12.ed. São Paulo: Pearson Prentice Hall, 2007.

LODI, J. B. A empresa familiar. São Paulo: Livraria Pioneira, 1978.

LOVELOCK, C.; WIRTZ, J. Marketing de serviços: Pessoas, tecnologia e resultados. 5. ed. São Paulo: Pearson Prentice Hall, 2006.

MAGALHÃES, G. Introdução à metodologia cientifica: caminhos da ciência e tecnologia. São Paulo: Ática, 2005.

MASCARENHAS, S. A. Metodologia Cientifica. São Paulo: Pearson Education do Brasil, 2012.

MORAIS, J. M. Crédito bancário no Brasil:

Participação das pequenas empresas e condições de acesso. Publicación de las Naciones Unidas.

2005. Disponivel em: < www.eclac.cl/publicaciones/xml/2/23902/

LCL2422-P>. Acesso em: 02 mai. 2014.

NEWTON, R . O gestor de projetos. São Paulo:

Pearson, 2011.

PAIXÃO, M. V. A Influência do consumidor nas decisões de marketing. Curitiba: Ibpex, 2012. 
POSER, D. V. Marketing de relacionamento: Maior lucratividade para empresas vencedoras. São Paulo: Manole, 2005.

RAMEZ, E.; SHAMKANT, B, N. Sistemas de banco de dados. 6. ed. São Paulo: Pearson Addison Wesley, 2011.

RAZZOLINI FILHO, E. Gerencia de serviços para a gestão comercial: um enfoque pratico, Curitiba: ibpex, 2010.

SABA, F. Gestão em atendimento: manual prático para academias e centros esportivos. São Paulo: Peason, 2012.

SAMARA, B. S.; MORSCH, M. A. Comportamento do consumidor: conceitos e casos. São Paulo: Prentice Hall, 2005.

SANTOS, D. A. Dos. A Importância da Gestão Financeira em Pequenas Empresas: enfoque em uma empresa familiar. 2008. 49 f. Alfenas: UNIFENAS, Disponível em: <http://www.sharepdf.com/a80652b8b10e4a40b9c0 c72681b3 ef50/ expandido14.htm>. Acesso em: $20 \mathrm{abr}$. 2014.

Recebido para publicação em 27/05/2015

Revisado em 22/03/2016

Aceito em 07/06/2016 